\title{
A Rapid, Reliable RP-UPLC Method for Large-Scale Analysis of Wheat HMW-GS Alleles
}

\author{
Su-Bin Lee ${ }^{1}$, Yu-Jeong Yang ${ }^{1}$, Sun-Hyung Lim ${ }^{2}$, Yong Q. Gu ${ }^{3}$ and Jong-Yeol Lee ${ }^{1, *}$ \\ 1 National Institute of Agricultural Science, RDA, Jeonju 54874, Korea; lsb36712@korea.kr (S.-B.L.); \\ yujinge@korea.kr (Y.-J.Y.) \\ 2 Division of Horticultural Biotechnology, Hankyong National University, Anseong 17579, Korea; \\ limsh2@hknu.ac.kr \\ 3 USDA-ARS, Western Regional Research Center, 800 Buchanan Street, Albany, CA 94710, USA; \\ yong.gu@usda.gov \\ * Correspondence: jy0820@korea.kr; Tel.: +82-63-238-4616
}

Citation: Lee, S.-B.; Yang, Y.-J.; Lim, S.-H.; Gu, Y.Q.; Lee, J.-Y. A Rapid, Reliable RP-UPLC Method for Large-Scale Analysis of Wheat HMW-GS Alleles. Molecules 2021, 26, 6174. https://doi.org/10.3390/ molecules26206174

Academic Editor: Giovanni D’Orazio

Received: 31 August 2021

Accepted: 10 October 2021

Published: 13 October 202

Publisher's Note: MDPI stays neutral with regard to jurisdictional claims in published maps and institutional affiliations.

Copyright: (C) 2021 by the authors. Licensee MDPI, Basel, Switzerland. This article is an open access article distributed under the terms and conditions of the Creative Commons Attribution (CC BY) license (https:// creativecommons.org/licenses/by/ $4.0 /)$

\begin{abstract}
High-molecular-weight glutenin subunits (HMW-GS) account for only $10 \%$ of total wheat storage proteins, but play an important role in the processing quality of wheat flour. Therefore, identifying HMW-GS alleles associated with good end-use quality provides important information for wheat breeders. To rapidly, accurately and reproducibly identify HMW-GS, we established an optimized reversed-phase ultra-performance liquid chromatography (RP-UPLC) method. Separation parameters were optimized using an ACQUITY UPLC Protein BEH $\mathrm{C}_{4}$ column and stepwise ACN gradient, and the separation patterns and retention times (RTs) of 22 subunits were comparatively analyzed in 16 standard wheat cultivars. All HMW-GS proteins were well separated within about $5.5 \mathrm{~min}$, and all analyses were complete within $12 \mathrm{~min}$. We distinguished the 16 subunits based on $\mathrm{RT}$, although three subunits in $1 \mathrm{Bx}\left(1 \mathrm{Bx} 7 / 1 \mathrm{Bx} 7^{\mathrm{OE}}\right.$ and $\left.1 \mathrm{Bx} 17\right)$ and three subunits in $1 \mathrm{By}\left(1 \mathrm{By} 8^{*}, 1 \mathrm{By} 9\right.$ and 1By15) had overlapping RTs; these were differentiated by SDS-PAGE. To distinguish $1 B \times 7$ and $1 \mathrm{~B} \times 7^{\mathrm{OE}}$, which differ in protein abundance, RP-UPLC was combined with PCR analysis of DNA junction markers. The optimized method was successfully applied to determine HMW-GS alleles in a large collection of bread wheat germplasm (1787 lines). This protocol is an appropriate option for selecting lines harboring favorable HMW-GS alleles in wheat breeding.
\end{abstract}

Keywords: HMW-GS; RP-UPLC; allelic analysis; large wheat germplasm

\section{Introduction}

Gluten, composed of polymeric glutenin and monomeric gliadin, is the primary factor that produces visco-elasticity in wheat dough and is important for wheat end-use quality [1,2]. Based on their molecular weights and primary structures, glutenins are divided into high-molecular-weight (HMW-GS, MW =67-100 kDa) and low-molecularweight (LMW-GS, MW = 32-35 kDa) glutenin subunits [3-5]. Each Glu-1 locus contains two linked genes that encode $x$-type and $y$-type HMW-GS. The $x$-type subunits generally have a higher molecular weight than the y-type subunits. In general, bread wheat contains three to five full length genes expressing HMW-GS, as Glu-A1 encodes an x-type subunit or is absent, Glu-B1 may encode both x- and y-type or only x-type HMW-GS and Glu-D1 encodes both types [1,6-8]. HMW-GS are crucial to dough quality because they form large polymeric backbones through disulfide bonds. This polymeric structure influences the rheological properties of dough and HMW-GS allelic variation is thought to account for $47-60 \%$ of wheat bread-making quality $[1,6,9]$. Therefore, the qualitative and quantitative effects of individual subunits are important for dough properties and bread-making quality [10].

The association between specific HMW-GS and bread-making quality has been extensively studied and can be quantified as the Glu-1 quality score, a numeric scale used in wheat breeding [11,12]. The Glu-1 quality score is defined as the sum of the contributions 
of all individual subunits from the Glu-A1, Glu-B1 and Glu-D1 loci in a specific wheat line. For example, at Glu-A1,1Ax1 and $1 \mathrm{Ax} 2^{*}$ contribute to a higher quality score than the null allele [1,7]. At Glu-B1, the subunit combination 1Bx17 + 1By18 results in higher dough strength than $1 \mathrm{Bx} 20+1 \mathrm{By} 20[1,13]$. Moreover, overexpression of $1 \mathrm{Bx} 7(1 \mathrm{Bx} 7 \mathrm{OE})$, which has two functional copies of 1Bx7genes, increases dough strength [14-17]. Glu-D1 is known to have a greater impact on bread-making quality than Glu-A1 and Glu-B1. In particular, $1 \mathrm{Dx} 5+1 \mathrm{Dy} 10$ is associated with superior end-use quality [1,7].

To determine the HMW-GS allelic composition of bread wheat, techniques such as sodium dodecyl sulfate-polyacrylamide gel electrophoresis (SDS-PAGE), polymerase chain reaction (PCR) analysis and reversed-phase high-performance liquid chromatography (RPHPLC) are commonly and widely used as alternatives to techniques requiring expensive instruments, such as high-performance capillary electrophoresis (HPCE) or matrix-assisted laser desorption/ionization time-of-flight mass spectrometry (MALDI-TOF-MS) [18-26]. Each of these three methods has drawbacks, however. Since SDS-PAGE distinguishes proteins by their differences in electrophoretic mobility, it is sometimes inadequate to distinguish subunits with similar molecular weights, resulting in incorrect identification. PCR analysis is simple and is commonly used in many breeding programs, but does not cover all HMW-GS allelic variations present in hexaploid wheat. Although RP-HPLC is fully automated, shows high reproducibility and provides the possibility for quantitative analysis, it also tends to have longer separation times and consumes larger amounts of reagents (such as solvents) than other methods [23].

Rapid and accurate identification of HMW-GS during a breeding program is of paramount importance for wheat quality improvement. In this study, we developed an optimized RP-UPLC method to identify these molecules by adopting a recently developed column to separate high-molecular-weight proteins and using stepwise gradient conditions to markedly shorten the time and increase resolution for bread wheat samples. With this optimized method and auxiliary methods, we successfully identified HMW-GS alleles of a large, worldwide collection of 1787 wheat lines, thus providing valuable resources for integrating wheat end-use quality data into breeding programs in the future.

\section{Results and Discussion}

\subsection{Optimization of RP-UPLC Conditions}

UPLC increases separation efficiency and provides superior resolution and sensitivity compared to classic HPLC because of its much wider range of linear velocities and its higher flow rates and back-pressures. Here, we optimized the RP-UPLC method for HMW-GS analysis by testing two columns and four mobile-phase gradient conditions to reduce the analysis time while increasing the resolution. Specifically, the ACQUITY UPLC peptide $\mathrm{BEH} \mathrm{C}_{18}$ column (particle size $1.7 \mu \mathrm{m}, 2.1 \mathrm{~mm} \times 100 \mathrm{~mm}$ id, $300 \AA$ A) and ACQUITY UPLC Protein BEH $C_{4}$ column (particle size $1.7 \mu \mathrm{m}, 2.1 \mathrm{~mm} \times 100 \mathrm{~mm}$ id, $300 \AA$ ), which are frequently used for peptide or protein separation, were tested. The same elution conditions were used for the glutenin fraction extracted from the reference cultivar Chinese Spring (CS), consisting of a column temperature of $60{ }^{\circ} \mathrm{C}$ and a flow rate of $0.4 \mathrm{~mL} / \mathrm{min}$ with an acetonitrile (ACN) linear gradient from $23 \%$ to $41 \%$ for $30 \mathrm{~min}$. Using the $\mathrm{C}_{4}$ column resulted in a faster elution time than the $\mathrm{C}_{18}$ column (Figure S1), prompting us to select the $\mathrm{C}_{4}$ column for further experiments. Column temperature and flow rate, which are critical separation parameters, showed good resolution at $60^{\circ} \mathrm{C}$ and $0.4 \mathrm{~mL} / \mathrm{min}$, respectively, when compared across several conditions (data not shown), and therefore this temperature and flow rate were used for later experiments. To establish analysis conditions for the mobile phase, two linear gradient conditions (Condition 1: ACN $23-41 \%$ for $30 \mathrm{~min}$; Condition 2: ACN 23-30\% for $10 \mathrm{~min}$ ) and two stepwise gradient conditions (Condition 3: ACN $23-28 \%$ for $2 \mathrm{~min}, 28-32 \%$ for $3 \mathrm{~min}$; Condition 4 : ACN $23-28 \%$ for $2 \mathrm{~min}, 28-30 \%$ for $1 \mathrm{~min}$ and $30 \%$ for $2 \mathrm{~min}$ ) were tested. The resulting chromatograms are shown in Figure 1. Under Condition 4, all subunits of HMW-GS in CS were effectively resolved, and all peaks eluted within about $5 \mathrm{~min}$, thus substantially reducing the analysis time. 


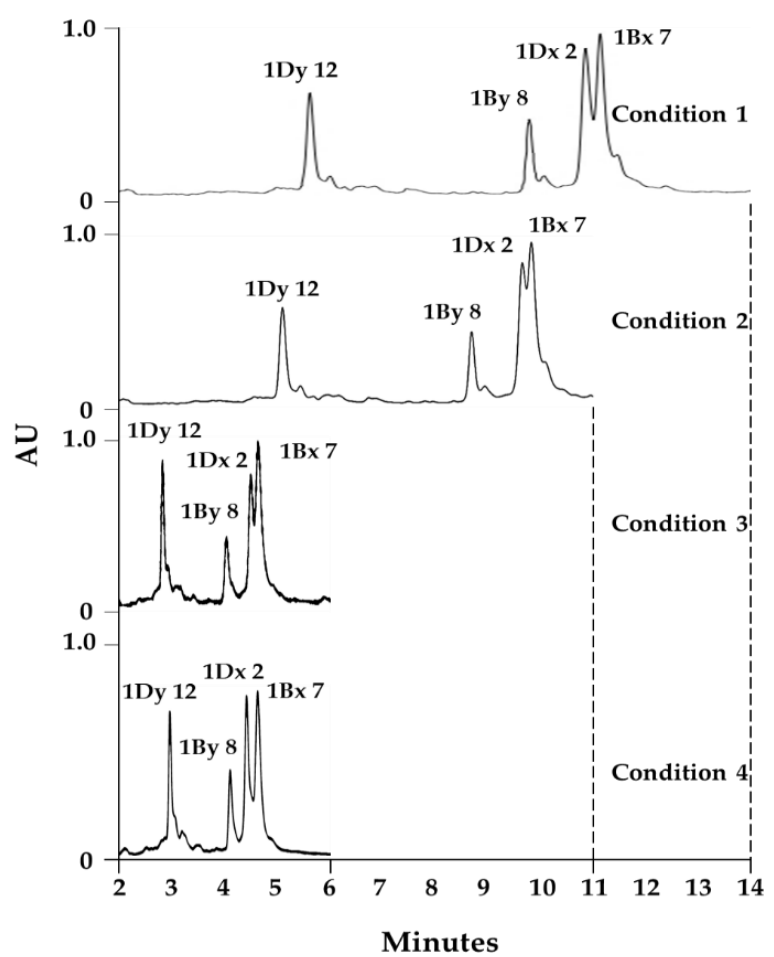

(a)

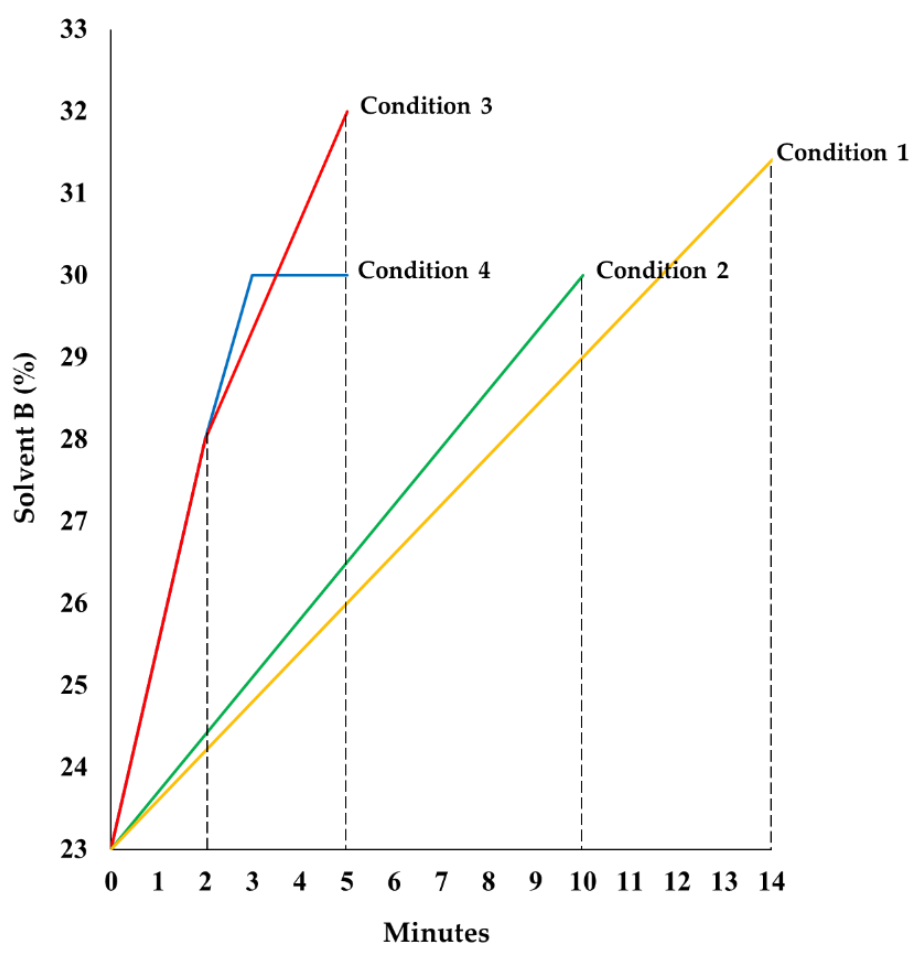

(b)

Figure 1. Optimization of RP-UPLC separation by changing ACN gradient conditions according to two linear gradients (Conditions 1 and 2) or two stepwise gradients (Conditions 3 and 4) using the same type of ACQUITY Protein BEH $300 \mathrm{C}_{4}$ column on samples from the Chinese Spring wheat cultivar. (a) Comparison of chromatogram patterns. (b) Detailed ACN gradient parameters in each condition.

To check the reproducibility of this optimized method, we performed the same analysis of the HMW-GS complement from the CS ten times under the same analytic condition and then calculated the average retention times (RTs), peak areas and relative standard deviations (RSD\%) for RTs for the four subunits. The RSD\% of RTs and peak areas varied by less than $0.21 \%$ and $1.18 \%$, respectively, across technical replicates, demonstrating the high reproducibility of this method (Figure S2 and Table S1).

The ACQUITY UPLC Protein BEH (Ethylene Bridged Hybrid) $\mathrm{C}_{4}$ column was designed to separate large molecular weight proteins and has shown excellent performance in separating many challenging proteins, overcoming the shortcomings of $100 \%$ silica-based materials [27-31]. Among the glutenin fraction, HMW-GS are more hydrophilic and larger than LMW-GS. Using the ACQUITY UPLC Protein BEH $\mathrm{C}_{4}$ column therefore allowed us to shorten elution time while retaining good separation. To further reduce analysis time as in Condition 4, two short gradients, such as $0-2$ min ACN $23-28 \%$ and $2-3$ min ACN $28-30 \%$, rather than the $0-3$ min ACN $23-30 \%$ gradient of Condition 3, were applied. Under this condition, the subunits 1Dy12 and 1Dy10 (Figures 2 and 3, Tables 1 and 2,) were successfully separated, which was not achieved in a previous study [25]. In addition, the separation of $1 \mathrm{Dx}$ and $1 \mathrm{Bx}$ improved as compared to Condition 3 due to the isocratic conditions of using $30 \% \mathrm{ACN}$ for $3-5 \mathrm{~min}$. These stepwise gradient conditions are an important reason for the observed combination of improved resolution and reduced analysis time. 


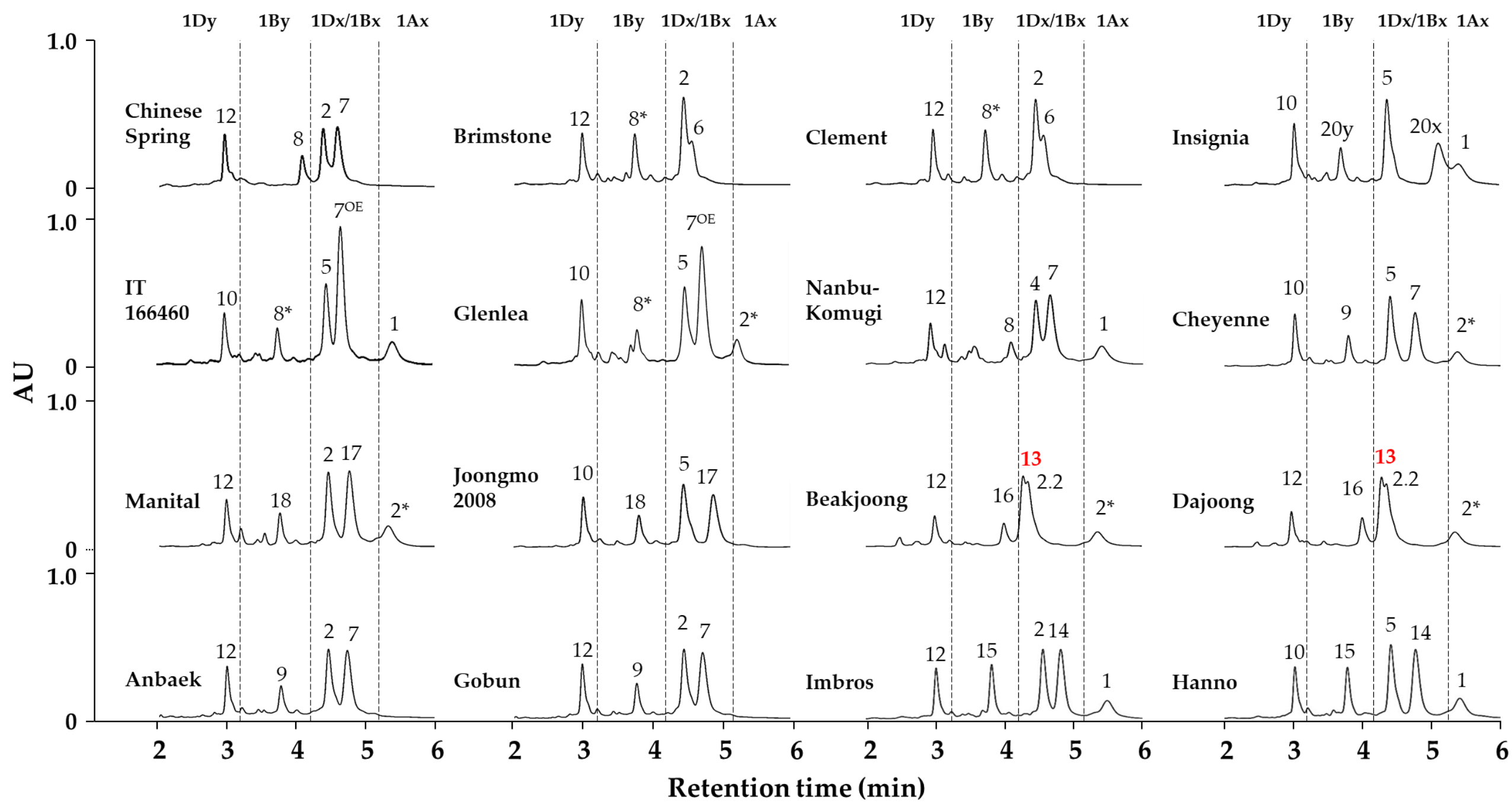

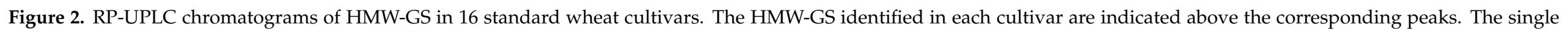
exception to the elution order, $1 \mathrm{Bx} 13$, is indicated in red. 


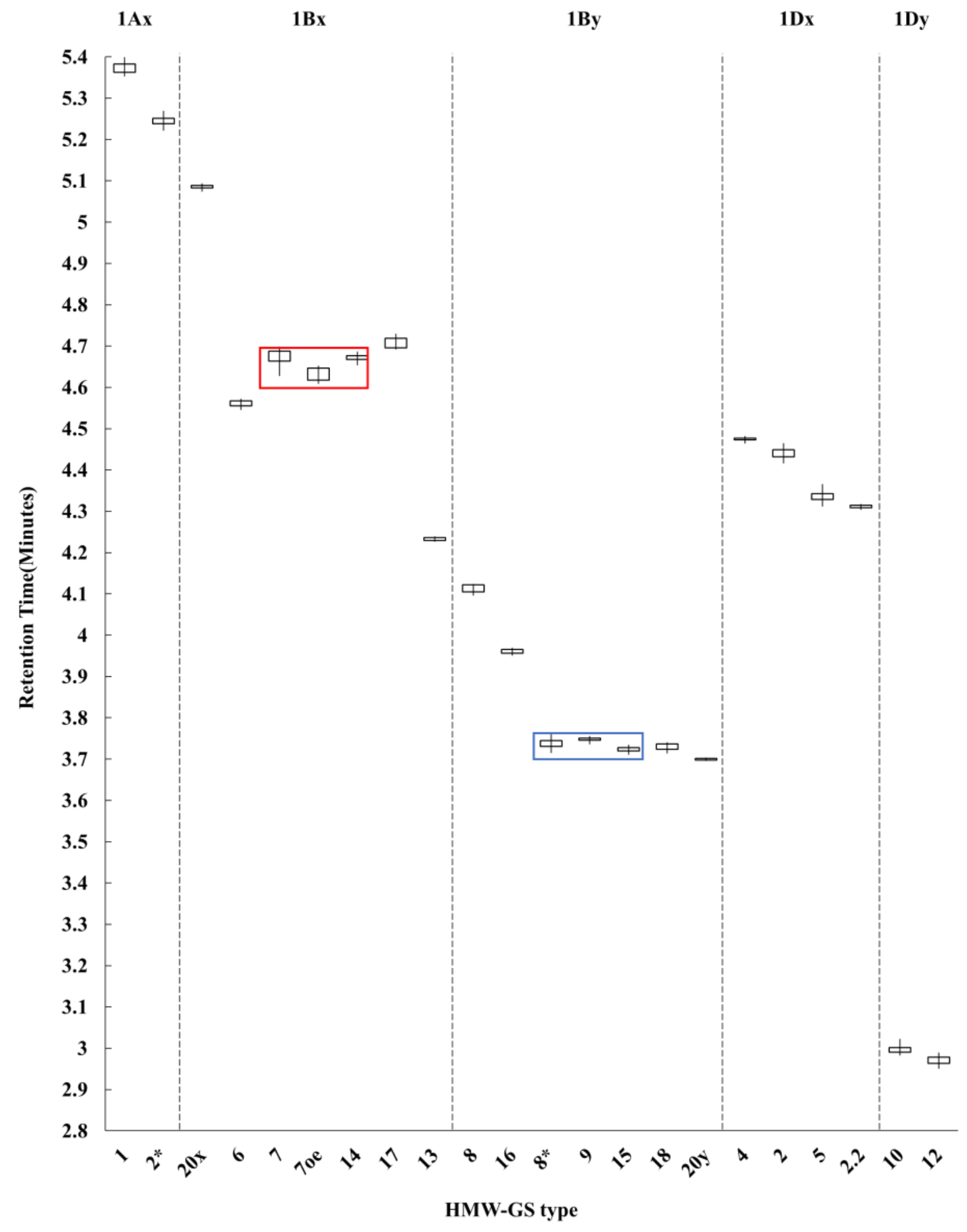

Figure 3. Box and whisker plot of retention times for $22 \mathrm{HMW}-\mathrm{GS}$ in 16 standard wheat cultivars. The red and blue boxes indicate subunits with overlapping retention times that cannot be distinguished from the other subunits on the basis of retention time alone. $1 \mathrm{~B} \times 7 / 1 \mathrm{Bx} 7^{\mathrm{OE}}$ and $1 \mathrm{Bx} 14$ in the red box and $1 \mathrm{By} 8^{*}, 1 \mathrm{By} 9$ and $1 \mathrm{By} 15$ in the blue box were identified by SDS-PAGE. 
Table 1. List of 16 standard wheat cultivars used in this study for HMW-GS analysis.

\begin{tabular}{|c|c|c|c|c|}
\hline \multirow{2}{*}{ Cultivar } & \multicolumn{3}{|c|}{ HMW-GS } & \multirow{2}{*}{ References } \\
\hline & Glu-A1 & Glu-B1 & Glu-D1 & \\
\hline Anbaek & Null & $7+9$ & $2+12$ & Jang et al. $[5,25]$ \\
\hline Baekjoong & $2^{*}$ & $13+16$ & $2.2+12$ & Jang et al. $[5,25]$ \\
\hline Brimstone & Null & $6+8^{*}$ & $2+12$ & Liu et al. [32] and Jang et al. [5,25] \\
\hline Cheyenne & $2^{*}$ & $7+9$ & $5+10$ & Dupont et al. [33] and Jang et al. $[5,25]$ \\
\hline Chinese Spring & Null & $7+8$ & $2+12$ & Liu et al. [32] and Jang et al. $[5,25]$ \\
\hline Clement & Null & $6+8^{*}$ & $2+12$ & Liu et al. [32] and Jang et al. [5,25] \\
\hline Dajoong & $2^{*}$ & $13+16$ & $2.2+12$ & Jang et al. $[5,25]$ \\
\hline Glenlea & $2^{*}$ & $7^{\mathrm{OE}}+8^{*}$ & $5+10$ & Naeem and Sapirstein [34] and Jang et al. [5,25] \\
\hline Gobun & Null & $7+9$ & $2+12$ & Jang et al. $[5,25]$ \\
\hline Hanno & 1 & $14+15$ & $5+10$ & Gao et al. [22] and Jang et al. [5] \\
\hline Imbros & 1 & $14+15$ & $2+12$ & Kazman et al. [35] and Jang et al. [5] \\
\hline Insignia & 1 & $20+20$ & $5+10$ & Branlard et al. [36] and Jang et al. $[5,25]$ \\
\hline IT166460 & 1 & $7^{\mathrm{OE}}+8^{*}$ & $2+12$ & Cho et al. [37] and Jang et al. $[5,25]$ \\
\hline Joongmo 2008 & Null & $17+18$ & $5+10$ & Jang et al. $[5,25]$ \\
\hline Manital & $2^{*}$ & $17+18$ & $2+12$ & Liu et al. [32] and Jang et al. [5] \\
\hline Nanbu-komugi & 1 & $7+8$ & $4+12$ & Liu et al. [32] and Jang et al. $[5,25]$ \\
\hline
\end{tabular}

Table 2. Reproducibility of retention times for $22 \mathrm{HMW-GS}$ determined by RP-UPLC in 16 standards.

\begin{tabular}{|c|c|c|c|c|}
\hline Type & HMW-GS & ${\text { Retention Time }(\min )^{1}}^{1}$ & RSD (\%) ${ }^{2}$ & Number of Cultivars $^{3}$ \\
\hline \multirow{2}{*}{$\mathrm{Ax}$} & 1 & $5.37 \pm 0.01$ & 0.25 & 5 \\
\hline & $2^{*}$ & $5.24 \pm 0.01$ & 0.22 & 5 \\
\hline \multirow{7}{*}{$\mathrm{Bx}$} & 6 & $4.56 \pm 0.01$ & 0.19 & 2 \\
\hline & 7 & $4.67 \pm 0.02$ & 0.42 & 5 \\
\hline & $7^{\mathrm{OE}}$ & $4.63 \pm 0.02$ & 0.35 & 2 \\
\hline & 13 & $4.23 \pm 0.01$ & 0.10 & 2 \\
\hline & 14 & $4.67 \pm 0.01$ & 0.16 & 2 \\
\hline & 17 & $4.71 \pm 0.01$ & 0.27 & 2 \\
\hline & $20 x$ & $5.09 \pm 0.01$ & 0.11 & 1 \\
\hline \multirow{7}{*}{ By } & 8 & $4.11 \pm 0.01$ & 0.24 & 2 \\
\hline & $8^{*}$ & $3.74 \pm 0.01$ & 0.31 & 4 \\
\hline & 9 & $3.75 \pm 0.01$ & 0.12 & 3 \\
\hline & 15 & $3.72 \pm 0.01$ & 0.17 & 2 \\
\hline & 16 & $3.96 \pm 0.01$ & 0.14 & 2 \\
\hline & 18 & $3.73 \pm 0.01$ & 0.23 & 2 \\
\hline & $20 y$ & $3.70 \pm 0.01$ & 0.07 & 1 \\
\hline \multirow{4}{*}{ Dx } & 2 & $4.44 \pm 0.01$ & 0.26 & 8 \\
\hline & 2.2 & $4.31 \pm 0.01$ & 0.11 & 2 \\
\hline & 4 & $4.48 \pm 0.01$ & 0.12 & 1 \\
\hline & 5 & $4.34 \pm 0.01$ & 0.32 & 5 \\
\hline \multirow{2}{*}{ Dy } & 10 & $3.00 \pm 0.01$ & 0.39 & 5 \\
\hline & 12 & $2.97 \pm 0.01$ & 0.33 & 11 \\
\hline
\end{tabular}

${ }^{1}$ Average retention times determined from 10 analyses per cultivar. ${ }^{2}$ Relative standard deviation. ${ }^{3} 16$ standard wheat cultivars listed in Table 1.

\subsection{Identification of HMW-GS Compositions in Standard Wheat Cultivars}

In this study, we identified the composition for $22 \mathrm{HMW}-\mathrm{GS}$ in 16 standard wheat cultivars, all reported in various earlier publications, using our optimized RP-UPLC method along with auxiliary methods (Table 1, Figures 2 and 3, Figures S3 and S4). The 22 subunits were: two of the $1 \mathrm{Ax}$ type (1Ax1 and $\left.1 \mathrm{Ax} 2^{*}\right)$, seven of the $1 \mathrm{Bx}$ type $\left(1 \mathrm{Bx} 6,1 \mathrm{Bx} 7,1 \mathrm{Bx} 7^{\mathrm{OE}}\right.$, $1 \mathrm{Bx} 13,1 \mathrm{Bx} 14,1 \mathrm{Bx} 17$ and $1 \mathrm{Bx} 20)$, seven of the 1By type (1By8, 1By8*,1By9, 1By15, 1By16, 1By18 and 1By20), four of the 1Dx type (1Dx2, 1Dx2.2, 1Dx4 and 1Dx5) and two of the 1Dy type (1Dy10 and 1D12). With the exception of the subunits 1Dx20 and 1Dy20 of cultivar 
Insignia, each remaining subunit was represented by at least two standard cultivars to improve the accuracy of the analysis (Table 1). All wheat cultivars were analyzed ten times, and the resulting average RTs and RSD\% of each subunit are reported in Table 2 . The RSD\% of RTs were less than $0.42 \%$, illustrating high reproducibility of the optimized method.

To determine whether each subunit can be distinguished based on retention time alone, the RT of each 22 HMW-GS was plotted in a box-and-whisker plot (Figure 3). 1Dy12, the most hydrophilic subunit, eluted at $2.970 \mathrm{~min}$ and $1 \mathrm{Ax1}$, the most hydrophobic subunit, eluted at $5.373 \mathrm{~min}$. Most HMW-GS eluted in the order (from fastest to slowest RT) $1 \mathrm{Dy}<1 \mathrm{By}<1 \mathrm{Dx}<1 \mathrm{Bx}<1 \mathrm{Ax}$, with the exception of 1Bx13. In the cultivars Baekjoong and Dajoong, HMW-GS eluted in the order 1Dy12<1By16<1Bx13<1Dx2.2<1Ax2* (Figures 2 and 3). The two subunits encoded by the Glu-A1 locus, $1 \mathrm{Ax} 1$ and $1 \mathrm{Ax} 2^{*}$, showed the greatest hydrophobicity among all HMW-GS, and they eluted last, making them easily distinguishable by RT, as shown in Figure 3.

Of the subunits encoded by the Glu-B1 locus, 1Bx subunits eluted more slowly than 1By subunits. The 1Bx6, 1Bx13,1Bx17 and 1Bx20 subunits could generally be distinguished, but not in the case of $1 \mathrm{~B} \times 7 / 1 \mathrm{~B} \times 7^{\mathrm{OE}}$ and $1 \mathrm{~B} \times 14$ due to their overlapping RTs. However, $1 \mathrm{Bx} 7 / 1 \mathrm{~B} \times 7^{\mathrm{OE}}$ and $1 \mathrm{Bx} 14$ were easily distinguishable by SDS-PAGE analysis based on their distinct electrophoretic mobility (Figure S3). The $1 \mathrm{~B} \times 7^{\mathrm{OE}}$ subunit typically exhibits higher abundance resulting from a duplication of the $1 \mathrm{Bx} 7$ gene. The $1 \mathrm{Bx} 7^{\mathrm{OE}}$ and $1 \mathrm{Bx} 7$ subunits were also distinguishable by PCR amplification using left and right junction primers between the duplicated segments and long terminal repeat (LTR) retrotransposon borders that gave rise to $1 \mathrm{Bx} 7^{\mathrm{OE}}[5,17]$. Therefore, the cultivars presumed to carry $1 \mathrm{Bx} 7$ or $1 \mathrm{Bx} 7^{\mathrm{OE}}$ based on measured RT during RP-UPLC analysis were genotyped for $1 \mathrm{Bx} 7^{\mathrm{OE}}$ (Figure S4). The higher accumulation of subunit $1 \mathrm{Bx} 7$ in cultivars harboring $1 \mathrm{Bx} 7^{\mathrm{OE}}$ increases dough strength and is considered the main reason for its large positive effect on bread-making quality $[15,16,32,38]$. Of the 1By subunits, 1By8, 1By16 and 1By20 were distinguishable based on their RT in RP-UPLC, while $1 B y 8^{*}, 1 B y 9,1 B y 15$ and $1 B y 18$ were not. However, the presence of the $1 B y 18$ can be inferred from the presence of the linked pair $1 \mathrm{Bx} 17$ $(1 \mathrm{Bx} 17+1 \mathrm{By} 18)$, as seen in Manital and Joongmo (2008). The remaining 1By8*,1By9 and 1By15 subunits were distinguishable only through SDS-PAGE analysis (Figure S3).

For the Glu-D1 locus, all the x-type (1Dx4, 1Dx5, 1Dx2 and 1Dx2.2) and y-type (1Dy10 and 1Dy12) subunits were distinguishable based on their non-overlapping RTs. In practical breeding programs for wheat quality improvement, it is also important to identify heterozygotes (e.g., $2+12 / 5+10$ ) among breeding lines. For this purpose, we extracted and mixed the two HMW-GS fractions from two varieties (Insignia and Manital) and RP-UPLC analyses were performed to test our optimized method. As a result, it was possible to identify subunits except for 1 Dy $10+12$ and $1 \mathrm{Ax} 1+2^{*}$, derived from these varieties (Figure S5). The two mixture peaks could be inferred as $10+12$ and 1 or/and $2^{*}$ by linked pairs or retention time.

Yan et al. [23] reported a rapid RP-UPLC method showing good separation patterns and high reproducibility for the identification of HMW-GS. Their method adopted an ACQUITY UPLC BEH $300 \mathrm{C}_{18}$ column (particle size $1.7 \mu \mathrm{m}, 2.1 \mathrm{~mm} \times 50 \mathrm{~mm}$ id, $300 \AA$ ) using the Waters ACQUITY UPLC system with separation parameters consisting of an ACN linear gradient of $21-47 \%$ for $30 \mathrm{~min}$, a flow rate of $0.55 \mathrm{~mL} / \mathrm{min}$ and a column temperature of $55^{\circ} \mathrm{C}$. With their method, all HMW-GS eluted in about $12 \mathrm{~min}$, resulting in good separation of 34 subunits from 111 wheat cultivars and wheat relatives, but the total analysis time was more than $30 \mathrm{~min}$. The optimized RP-UPLC method presented here used a column designed for large proteins combined with innovative stepwise ACN gradients to significantly reduce HMW-GS elution time to about $5.5 \mathrm{~min}$, for a total analysis time of about $12 \mathrm{~min}$. Among the 22 subunits, six HMW-GS with overlapping RTs or whose encoding genes were not linked to other HMW-GS pairs were identified by SDS-PAGE and PCR analysis to prevent potential misleading results when the RP-UPLC method was used alone, thus increasing the reliability of the analysis. 


\subsection{Applying the Optimized Method to a Large Collection of Wheat Germplasm}

The optimized method established in this study was then used to determine the HMWGS complement in a large-scale wheat genetic resource consisting of 1787 wheat lines from the National Agrobiodiversity Center in Korea. The 22 subunits from the 16 standard wheat cultivars tested above were used as external standards for HMW-GS allelic analysis. The results of this HMW-GS allelic analysis are listed in Table S2. This germplasm collection comprised wheat cultivars, breeding lines and collected accessions from South and North Korea and around the world. All wheat samples in the study were characterized by the presence of three to five subunits, which is a typical HMW-GS profile for hexaploid wheat (Table S2).

The frequencies of $27 \mathrm{HMW}-\mathrm{GS}$ alleles at Glu-1 were determined for all 1787 wheat lines (Table 3). At Glu-A1, we obtained frequencies of $23.29 \%, 43.31 \%$ and $33.30 \%$ for the three alleles $1 \mathrm{Ax} 1,1 \mathrm{Ax2}$ and null, respectively. Glu-B1 presented the largest number of alleles (17) among Glu-1 loci, with 1Bx7 + 1By9 (28.15\%), 1Bx7 + 1By8 (26.47\%), 1Bx7 + 1By8* $(12.26 \%), 1 \mathrm{~B} \times 17+1 \mathrm{By} 18(12.26 \%)$ and $1 \mathrm{~B} \times 20+1 \mathrm{By} 20(6.72 \%)$, five alleles, accounting for $85.86 \%$ of all $\mathrm{Glu}-\mathrm{B} 1$ alleles. Allelic pairs were identified at $\mathrm{Glu}-\mathrm{B} 1$ with $1 \mathrm{Bx} 7^{\mathrm{OE}}$ known to be beneficial for bread-making quality: $1 \mathrm{Bx} 7^{\mathrm{OE}}+1 \mathrm{By} 8^{*}$ and $1 \mathrm{Bx} 7^{\mathrm{OE}}+1 \mathrm{By} 9$, in 33 $(1.85 \%)$ and two $(0.11 \%)$ accessions, respectively. We determined the genotype at $1 \mathrm{Bx} 7^{\mathrm{OE}}$ by PCR amplification with left and right junction primers for germplasm in which $1 \mathrm{Bx} 7$ and $1 \mathrm{~B} \times 7^{\mathrm{OE}}$ could not be separated by RP-UPLC analysis (Figure S4). The $1 \mathrm{~B} \times 7^{\mathrm{OE}}+1 \mathrm{By} 9$ pair was described in Zheng et al. [39] in one out of 485 common wheat landraces collected from the Yangtze River basin in China. In this study, we identified two (line 504 and 620) lines from the collection of 1787 lines, both of which were bread wheat varieties from Mexico. At Glu-D1, three pairs [1Dx5 + 1Dy10 (46.84\%), 1Dx2 + 1Dy12 (42.42\%) and $1 \mathrm{Dx} 2.2+1 \mathrm{Dy} 12(8.39 \%)]$ among the seven alleles accounted for $97.65 \%$ of the lines present in the germplasm collection.

Table 3. Allelic frequency of HMW-GS inferred by the optimized method in 1787 wheat germplasm.

\begin{tabular}{|c|c|c|c|c|}
\hline Locus & HMW-GS & Allele * & Number of Cultivars & Frequency (\%) \\
\hline \multirow{3}{*}{ Glu-A1 } & 1 & Glu-A1a & 418 & 23.39 \\
\hline & $2^{*}$ & Glu-A1b & 774 & 43.31 \\
\hline & Null & Glu-A1c & 595 & 33.30 \\
\hline \multirow{17}{*}{ Glu-B1 } & 6 & Glu-B1-1d & 8 & 0.45 \\
\hline & $6+8^{*}$ & Glu-B1ca & 65 & 3.64 \\
\hline & 7 & Glu-B1a & 64 & 3.58 \\
\hline & $7+8$ & Glu-B1b & 473 & 26.47 \\
\hline & $7+8^{*}$ & Glu-B1ce & 219 & 12.26 \\
\hline & $7+9$ & Glu-B1c & 503 & 28.15 \\
\hline & $7^{\mathrm{OE}}+8^{*}$ & Glu-B1al & 33 & 1.85 \\
\hline & $7^{\mathrm{OE}}+9$ & unknown & 2 & 0.11 \\
\hline & 8 & Glu-B1aj & 1 & 0.06 \\
\hline & $8^{*}$ & Glu-B1-2o & 1 & 0.06 \\
\hline & 9 & Glu-B1-2b & 1 & 0.06 \\
\hline & $13+16$ & Glu-B1f & 67 & 3.75 \\
\hline & $14+15$ & Glu-Bih & 2 & 0.11 \\
\hline & 15 & Glu-B1-2e & 7 & 0.39 \\
\hline & $17+18$ & Glu-B1i & 219 & 12.26 \\
\hline & $20 y$ & Glu-B1-2z & 2 & 0.11 \\
\hline & $20+20$ & Glu-B1e & 120 & 6.72 \\
\hline \multirow{7}{*}{ Glu-D1 } & $2+12$ & Glu-D1a & 758 & 42.42 \\
\hline & 2 & Glu-D1k & 1 & 0.06 \\
\hline & $2.2+12$ & Glu-D1f & 150 & 8.39 \\
\hline & $4+12$ & Glu-Dic & 38 & 2.13 \\
\hline & 5 & Glu-D1-1d & 2 & 0.11 \\
\hline & $5+10$ & Glu-D1d & 837 & 46.84 \\
\hline & 12 & Glu-D1l & 1 & 0.06 \\
\hline
\end{tabular}

* Gene nomenclature system based on Catalogue of gene Symbols for Wheat. 
Our analysis also allowed the identification of wheat lines with unique null allelic combinations. The Glu-B1 locus commonly harbors genes encoding $1 \mathrm{Bx}+1 \mathrm{By}$ or only $1 \mathrm{Bx}$ alleles, but we detected $121 \mathrm{Bx}$ nulls (one with $1 \mathrm{By} 8$, one with $1 \mathrm{By} 8^{*}$, one with $1 \mathrm{By} 9$, seven with 1By15 and two with 1By20). Similarly, 1Dx + 1Dy alleles are typical at Glu-D1, but we identified one 1Dx null (with 1Dy12) and three 1Dy nulls (one with 1Dx2, two with 1Dx5) (Figure 4, Table S2).

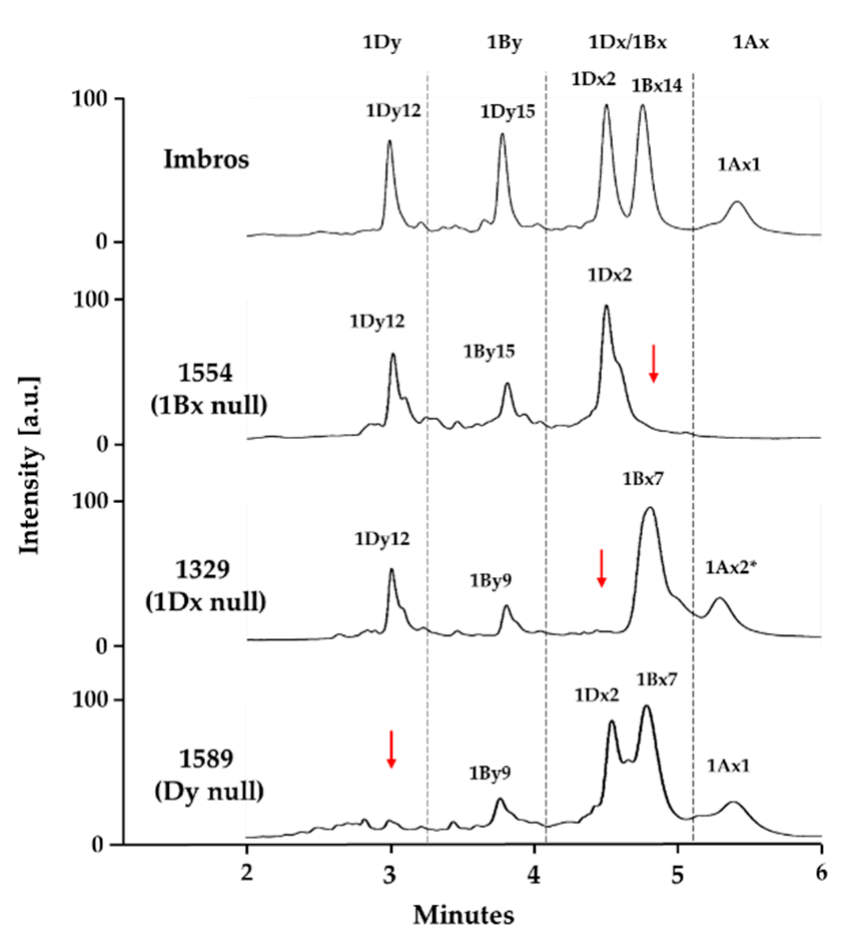

(a)

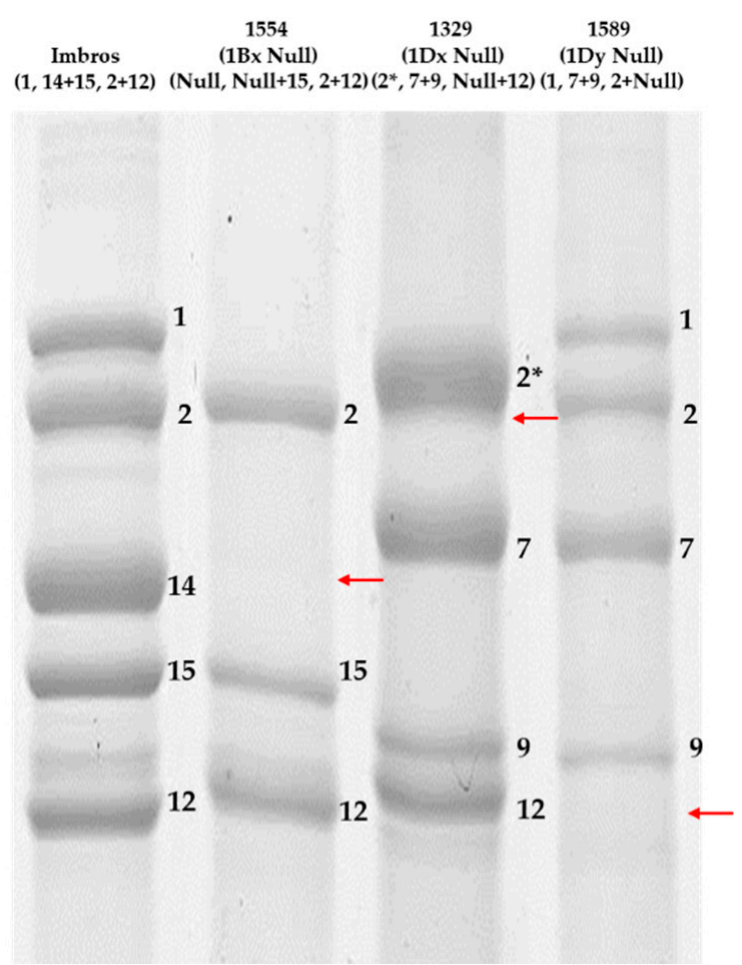

(b)

Figure 4. Representative RP-UPLC chromatograms (a) and SDS-PAGE profiles (b) of 1Bx, 1Dx and 1By null wheat lines. The regions lacking the respective HMW-GS are indicated by red arrows.

The 1787 accessions represented 95 possible allelic combinations (Table S3). Allelic combinations associated with good bread-making quality that should be included at each locus were: either $1 \mathrm{Ax} 1$ or $1 \mathrm{Ax} 2^{*}$ at Glu-A1; any one of the pairs $1 \mathrm{Bx} 7+1 \mathrm{By} 8$, $1 \mathrm{Bx} 17+1 \mathrm{By} 18,1 \mathrm{Bx} 7^{\mathrm{OE}}+1 \mathrm{By} 8^{*}$ and $1 \mathrm{Bx} 7^{\mathrm{OE}}+1 \mathrm{By} 9$ at Glu-B1, and $1 \mathrm{Dx} 5+1 \mathrm{Dy} 10$ at Glu-D1, which corresponded to 248 lines, accounting for $13.88 \%$ of the total.

RP-UPLC is a relatively easy-to-use technique that has recently been widely implemented. Although our method showed a short processing time per sample, one limitation is that samples will be run one by one with a single machine, while multiple samples can be run simultaneously on a single SDS page gel. The optimized RP-UPLC method presented here is a powerful and reliable method to determine HMW-GS composition in breeding programs for wheat quality improvement. In this HMW-GS analysis of largescale genetic resources, we highlighted wheat lines with allelic combinations conveying good bread-making quality that can be directly included in breeding programs for quality improvement.

\section{Materials and Methods}

\subsection{Plant Materials}

Seeds for sixteen standard bread wheat (Triticum aestivum L.) cultivars were kindly provided by the U.S. National Plant Germplasm System and the National Institute of Crop Science (NICS, Jeonju, Korea), as listed in Table S2. Seeds for 1787 hexaploid wheat lines 
were obtained from the National Agrobiodiversity Center (Jeonju, Korea) and grown at NICS in 2017 as reported in Jang et al. [26]. All grain samples used in the experiment were crushed with a cyclone sample mill (Udy Corporation, Fort Collins, CO, USA), and were turned into flour.

\subsection{Glutenin Extraction and Precipitation}

The glutenin fraction was extracted from wheat flour according to Singh et al. [40] with minor modifications. To remove monomeric gliadins, $1 \mathrm{~mL}$ of $50 \%(v / v)$ propanol was added to $50 \mathrm{mg}$ of wheat flour, incubated at $65^{\circ} \mathrm{C}$ for $30 \mathrm{~min}$ and centrifuged at $10,000 \times \mathrm{g}$ for $10 \mathrm{~min}$, after which the supernatant was discarded. This step was repeated twice. To extract polymeric glutenin, $500 \mu \mathrm{L}$ of extraction buffer $(50 \%(v / v)$ propanol, $80 \mathrm{mM}$ Tris- $\mathrm{HCl} \mathrm{pH} 8.0$ containing $1 \%(w / v)$ dithiothreitol (DTT)) was added to the above pellet, incubated at $65^{\circ} \mathrm{C}$ for $30 \mathrm{~min}$ and centrifuged at $10,000 \times g$ for $5 \mathrm{~min}$. Subsequently, another $500 \mu \mathrm{L}$ of extraction buffer containing $1.4 \%(v / v)$ 4-vinylpyridine instead of $1 \%$ DTT was added and the sample was incubated at $65{ }^{\circ} \mathrm{C}$ for $15 \mathrm{~min}$ for glutenin alkylation. After centrifugation at $10,000 \times g$ for $5 \mathrm{~min}$, the supernatant was transferred to a new tube and stored at $-80^{\circ} \mathrm{C}$ for further experiments.

Glutenin precipitation for RP-UPLC analysis was performed as described by Melas et al. [41]. The glutenin extracts were precipitated by the addition of acetone to a final concentration of $40 \%(v / v)$. Then, $600 \mu \mathrm{L}$ of cold acetone was added to $900 \mu \mathrm{L}$ of the collected supernatant in a new $2 \mathrm{~mL}$ tube and incubated at $-20^{\circ} \mathrm{C}$ overnight. After centrifugation at $10,000 \times g$ at $4^{\circ} \mathrm{C}$ for $10 \mathrm{~min}$, the resulting protein pellet was rinsed with $500 \mu \mathrm{L}$ acetone and centrifuged at $4{ }^{\circ} \mathrm{C}$ for $10 \mathrm{~min}$. Finally, the protein pellet was completely air-dried.

For SDS-PAGE analysis, the extracted glutenin fractions were precipitated using $15 \%(v / v)$ trichloroacetic acid (TCA)/acetone at $-20{ }^{\circ} \mathrm{C}$ overnight. Then, $50 \mu \mathrm{L}$ of the supernatant and $200 \mu \mathrm{L}$ of cold acetone containing $15 \%(v / v)$ TCA were mixed in a $1.5 \mathrm{~mL}$ tube and incubated at $-20^{\circ} \mathrm{C}$ overnight. After centrifugation at $10,000 \times \mathrm{g}$ at $4{ }^{\circ} \mathrm{C}$ for 10 $\mathrm{min}$, the resulting protein pellet was rinsed with $200 \mu \mathrm{L}$ of acetone containing $0.07 \%(w / v)$ DTT and centrifuged at $4{ }^{\circ} \mathrm{C}$ for $10 \mathrm{~min}$. Finally, the protein pellet was completely air-dried.

\subsection{RP-UPLC}

RP-UPLC analysis was performed on an ACQUITY UPLC H-Class System (Waters Corp, Milford, MA, USA). All mobile-phase solvents for RP-UPLC analysis were of high purity and were purchased from Fisher Scientific (USA).

To establish optimal RP-UPLC analysis conditions for HMW-GS, the ACQUITY UPLC Protein $\mathrm{BEH} \mathrm{C}_{4}$ Column (Waters Corp, USA, particle size $1.7 \mu \mathrm{m}, 2.1 \times 100 \mathrm{~mm}$ id, pore size $300 \AA$ ) and ACQUITY UPLC Peptide BEH $C_{18}$ Column (Waters Corp, USA, particle size $1.7 \mu \mathrm{m}, 2.1 \times 100 \mathrm{~mm}$ id, pore size $300 \AA$ ) were tested with the same analytical parameters. Water and acetonitrile $(\mathrm{ACN})$, both containing $0.06 \%(v / v)$ trifluoroacetic acid (TFA), were used as mobile-phase solvents $A$ and $B$, respectively. The dried protein pellet was completely resuspended in $200 \mu \mathrm{L}$ of $20 \%(v / v)$ ACN containing $0.06 \%$ TFA and filtered using a $0.22 \mu \mathrm{m}$ PVDF syringe filter (Whatman, UK). Four microliters of each sample was injected for separation. HMW-GS were eluted using a linear gradient of $23-41 \%$ solvent $\mathrm{B}$ for $30 \mathrm{~min}$ with a flow rate of $0.4 \mathrm{~mL} / \mathrm{min}$ and a column temperature of $60{ }^{\circ} \mathrm{C}$ and monitored at a wavelength of $210 \mathrm{~nm}$.

After determining that the ACQUITY UPLC Protein BEH $\mathrm{C}_{4}$ Column performed better, four mobile-phase gradient conditions were tested: two linear gradients (Condition 1: solvent B 23-41\% for $30 \mathrm{~min}$; Condition 2: solvent B 23-30\% for $10 \mathrm{~min}$ ) and two stepwise gradients (Condition 3: solvent B 23-28\% for 0-2 min, 28-32\% for 2-5 min; Condition 4: solvent B $23-28 \%$ for $0-2 \mathrm{~min}, 28-30 \%$ for $2-3 \mathrm{~min}, 30 \%$ for $3-5 \mathrm{~min}$ ). Finally, optimal HMW-GS elution conditions were determined to be Condition 4 with a washing step (solvent B $30-90 \%$ for $30 \mathrm{sec}, 90 \%$ for $1.5 \mathrm{~min}, 90-23 \%$ for $30 \mathrm{sec}, 23 \%$ for $4.5 \mathrm{~min}$ ), with the remaining analytical parameters as above. 


\subsection{SDS-PAGE}

SDS-PAGE analysis was performed on a Hoefer SE260 Mighty Small II electrophoresis unit with reference to Jang et al. [25]. Each precipitated protein pellet was resuspended in $20 \mu \mathrm{L}$ of sample buffer $(50 \mathrm{mM}$ Tris- $\mathrm{HCl} \mathrm{pH} 6.8,2 \%(v / v) \beta$-mercaptoethanol, $2 \%(w / v)$ SDS, $20 \%(v / v)$ glycerol and $0.01 \%(w / v)$ bromophenol blue) and $4 \mu \mathrm{L}$ was loaded onto a 12.5\% SDS-PAGE gel. Xpert Prestained Protein Marker (10-240 kDa, GenDEPOT, Katy, TX, USA) was used as protein marker. After electrophoresis, the gel was stained with $1 \%$ $(w / v)$ Coomassie Brilliant Blue R-250 and destained in destaining solution (water:acetic acid:methanol $(8: 1: 1 v / v / v))$.

\subsection{Genomic DNA Extraction and PCR Analysis}

Genomic DNA was extracted from $50 \mathrm{mg}$ of wheat flour for each wheat cultivar using the GeneAll Exgene Plant SV mini kit (GeneAll, Seoul, Korea) following the manufacturer's instructions. The extracted genomic DNA was quantified and its quality assessed on a NanoDrop spectrophotometer (Thermo Scientific, Waltham, MA, USA), and then it was diluted to $50 \mathrm{ng} / \mu \mathrm{L}$. PCR analysis to discriminate between $1 \mathrm{Bx} 7$ and $1 \mathrm{Bx} 77^{\mathrm{OE}}$ was performed using the method described by $[5,17]$. PCR was performed in a reaction volume of $20 \mu \mathrm{L}$ using $150 \mathrm{ng}$ of genomic DNA, $1.25 \mathrm{U}$ of Go Taq DNA polymerase (Promega, USA), $1 \times$ Green Go Taq reaction buffer (containing $1.5 \mathrm{mM} \mathrm{MgCl}_{2}$ ), $200 \mu \mathrm{M}$ of dNTP mix (Bioneer, Daejeon, Korea) and 10 pmol each of forward and reverse primers. Left junction primers were: forward $5^{\prime}$-ACGTGTCCAAGCTTTGGTTC- ${ }^{\prime}$ and reverse $5^{\prime}$-GATTGGTGGGTGGATACAGG- ${ }^{\prime}$, and right junction primers were forward $5^{\prime}$-CCACTTCCAAGGTGGGACTA- $3^{\prime}$ and reverse 5'-TGCCAACACAAAAGAAGCTG-3' [17]. Amplification conditions for PCR were an initial cycle at $95^{\circ} \mathrm{C}$ for $5 \mathrm{~min}$, followed by 34 cycles of $94{ }^{\circ} \mathrm{C}$ for $30 \mathrm{~s}, 57^{\circ} \mathrm{C}$ for $30 \mathrm{~s}$ and $72{ }^{\circ} \mathrm{C}$ for $1 \mathrm{~min}$, and then a final extension at $72{ }^{\circ} \mathrm{C}$ for $5.25 \mathrm{~min}$. PCR products were resolved on 1.5-2.0\% agarose gels in $0.5 \times$ Tris borate EDTA (TBE) buffer, stained with ethidium bromide and visualized under UV.

\section{Conclusions}

The HMW-GS composition of wheat grains has key implications for grain quality for specific end uses, with different alleles providing advantages for different uses, from noodles to bread dough. This study presented an optimized RP-UPLC method for determining the HMW-GS alleles in wheat and validated this method in a large collection of bread wheat germplasm (1787 lines). The resulting protocol provides a valuable tool for selecting lines harboring favorable HMW-GS alleles in wheat breeding, particularly when combined with auxiliary methods to identify alleles whose encoded proteins migrate with similar retention times. Future research in the area may further increase the resolution of the analysis and improve throughput.

Supplementary Materials: The following are available online. Figure S1: RP-UPLC chromatograms of the glutenin fraction in Chinese Spring using (a) ACQUITY Peptide BEH $\mathrm{C}_{18}$ column and (b) ACQUITY Protein BEH $\mathrm{C}_{4}$ column eluted with the same linear ACN gradient of $23-41 \%$ for 30 min; Figure S2: Overlap of HMW-GS chromatograms run 10 times using the optimized RP-UPLC method from the Chinese Spring; Figure S3: SDS-PAGE analysis of HMW-GS in Glenlea, Cheyenne and Hanno. Two group of HMW-GS, which are indistinguishable by RP-UPLC due to overlap retention time, are underlined in blue (1Bx7/1Bx7 $7^{\mathrm{OE}}$ and $\left.1 \mathrm{~B} \times 14\right)$ and red (1By8*, $1 \mathrm{By} 9$ and 1By15); Figure S4: PCR amplification to determine the $1 B \times 7^{\mathrm{OE}}$ genotype. Left and Right refer to the junction of the LTR retrotransposon associated with $1 \mathrm{Bx} 77^{\mathrm{OE}}$ [17]. The left and right junction of the retroelement and the duplicated region generated 447-bp and 844-bp amplicons respectively in $1 \mathrm{Bx} 7^{\mathrm{OE}}$. Cheyenne $(\mathrm{CH})$ and Chinese Spring $(\mathrm{CS})$ were used as negative controls for $1 \mathrm{Bx} 7^{\mathrm{OE}}$. Glenlea (GL) and IT166460 (IT) were used as positive controls for $1 \mathrm{Bx} 77^{\mathrm{OE}}$ [41]. Marker (M) is 100bp Plus DNA Ladder; Table S1: Reproducibility of HMW-GS analysis in Chinese Spring by RP-UPLC; Figure S5: RP-UPLC chromatograms of the HMW-GS in (a) Insignia (b) Manital and (c) mixture of Insignia and Manital; Table S2: HMW-GS compositions identified by the optimized method in 1787 wheat germplasm. Wheat accessions harboring HMW-GS allelic combination associated with good bread-making quality and 
unique null subunits are marked in the note; Table S3: Frequency of HMW-GS allelic combination in 1787 wheat germplasm. HMW-GS allelic combinations associated with good bread-making quality are indicated in the note.

Author Contributions: Conceptualization, S.-B.L. and J.-Y.L.; formal analysis, S.-B.L., Y.-J.Y., S.H.L., Y.Q.G. and J.-Y.L.; funding acquisition, J.-Y.L.; investigation, S.-B.L., Y.-J.Y., S.-H.L. and J.-Y.L.; methodology, S.-B.L. and J.-Y.L.; project administration, J.-Y.L.; supervision, J.-Y.L.; validation, S.-B.L. and J.-Y.L.; visualization, S.-B.L.; writing-original draft, S.-B.L. and J.-Y.L.; writing-review and editing, S.-B.L., Y.-J.Y., S.-H.L., Y.Q.G. and J.-Y.L. All authors have read and agreed to the published version of the manuscript.

Funding: This work was supported by a grant from the New Breeding Technologies Development Program (Project No. PJ01476902), Rural Development Administration, Korea.

Institutional Review Board Statement: Not applicable.

Informed Consent Statement: Not applicable.

Data Availability Statement: The data presented in this study are available in supplementary material.

Conflicts of Interest: The authors declare no conflict of interest.

Sample Availability: Samples of the compounds are not available from the authors.

\section{References}

1. Payne, P.I. Genetics of wheat storage proteins and the effect of allelic variation on bread-making quality. Annu. Rev. Plant Physiol. 1987, 38, 141-153. [CrossRef]

2. Macritchie, F. Physicochemical Properties of Wheat Proteins in Relation to Functionality. In Advances in Food and Nutrition Research; Kinsella, J.E., Ed.; Academic Press: Cambridge, MA, USA, 1992; Volume 36, pp. 1-87.

3. Wieser, H. Chemistry of gluten proteins. Food Microbiol. 2007, 24, 115-119. [CrossRef]

4. D'Ovidio, R.; Masci, S. The low-molecular-weight glutenin subunits of wheat gluten. J. Cereal Sci. 2004, 39, 321-339. [CrossRef]

5. Jang, Y.-R.; Cho, K.; Kim, S.W.; Altenbach, S.B.; Lim, S.-H.; Sim, J.-R.; Lee, J.-Y. Development of an Optimized MALDI-TOF-MS Method for High-Throughput Identification of High-Molecular-Weight Glutenin Subunits in Wheat. Molecules 2020, $25,4347$. [CrossRef] [PubMed]

6. Wrigley, C.W. Giant proteins with flour power. Nature 1996, 381, 738-739. [CrossRef]

7. Payne, P.I.; Lawrence, G.J. Catalogue of alleles for the complex gene loci, Glu-A1, Glu-B1, and Glu-D1 which code for highmolecular-weight subunits of glutenin in hexaploid wheat. Cereal Res. Commun. 1983, 11, $29-35$.

8. Shewry, P.; Halford, N.; Tatham, A. High molecular weight subunits of wheat glutenin. J. Cereal Sci. 1992, 15, 105-120. [CrossRef]

9. Rakszegi, M.; Bekes, F.; Lang, L.; Tamas, L.; Shewry, P.; Bedő, Z. Technological quality of transgenic wheat expressing an increased amount of a HMW glutenin subunit. J. Cereal Sci. 2005, 42, 15-23. [CrossRef]

10. Barro, F.; Rooke, L.; Békés, F.; Gras, P.; Tatham, A.S.; Fido, R.; Lazzeri, P.A.; Shewry, P.R.; Barceló, P. Transformation of wheat with high molecular weight subunit genes results in improved functional properties. Nat. Biotechnol. 1997, 15, 1295-1299. [CrossRef]

11. Payne, P.I.; Nightingale, M.A.; Krattiger, A.F.; Holt, L.M. The relationship between HMW glutenin subunit composition and the bread-making quality of British-grown wheat varieties. J. Sci. Food Agric. 1987, 40, 51-65. [CrossRef]

12. Rogers, W.; Payne, P.; Harinder, K. The HMW glutenin subunit and gliadin compositions of German-grown wheat varieties and their relationship with bread-making quality. Plant Breed. 1989, 103, 89-100. [CrossRef]

13. Gianibelli, M.; Larroque, O.; MacRitchie, F.; Wrigley, C. Biochemical, genetic, and molecular characterization of wheat endosperm proteins. Cereal Chem. 2001, 78, 635-646. [CrossRef]

14. Vawser, M.; Cornish, G.B. Over-expression of HMW glutenin subunit Glu-B1 7x in hexaploid wheat varieties (Triticum aestivum). Aust. J. Agric. Res. 2004, 55, 577-588. [CrossRef]

15. Butow, B.; Ma, W.; Gale, K.; Cornish, G.; Rampling, L.; Larroque, O.; Morell, M.; Békés, F. Molecular discrimination of Bx7 alleles demonstrates that a highly expressed high-molecular-weight glutenin allele has a major impact on wheat flour dough strength. Theor. Appl. Genet. 2003, 107, 1524-1532. [CrossRef]

16. Radovanovic, N.; Cloutier, S.; Brown, D.; Humphreys, D.; Lukow, O. Genetic variance for gluten strength contributed by high molecular weight glutenin proteins. Cereal Chem. 2002, 79, 843-849. [CrossRef]

17. Ragupathy, R.; Naeem, H.A.; Reimer, E.; Lukow, O.M.; Sapirstein, H.D.; Cloutier, S. Evolutionary origin of the segmental duplication encompassing the wheat GLU-B1 locus encoding the overexpressed Bx7 (Bx7 OE) high molecular weight glutenin subunit. Theor. Appl. Genet. 2008, 116, 283-296. [CrossRef]

18. Bietz, J.A. Separation of cereal proteins by reversed-phase high-performance liquid chromatography. J. Chromatogr. A 1983, 255, 219-238. [CrossRef]

19. Courcoux, P.; Serot, T.; Larre, C.; Popineau, Y. Characterization and identification of wheat cultivars by multi-dimensional analysis of reversed-phase high-performance liquid chromatograms. J. Chromatogr. A 1992, 596, 225-232. [CrossRef] 
20. Cozzolino, R.; Giorgi, S.D.; Fisichella, S.; Garozzo, D.; Lafiandra, D.; Palermo, A. Matrix-assisted laser desorption/ionization mass spectrometric peptide mapping of high molecular weight glutenin subunits 1Bx7 and 1Dy10 in Cheyenne cultivar. Rapid Commun. Mass Spectrom. 2001, 15, 778-787. [CrossRef]

21. Dong, K.; Hao, C.; Wang, A.; Cai, M.; Yan, Y. Characterization of HMW glutenin subunits in bread and tetraploid wheats by reversed-phase high-performance liquid chromatography. Cereal Res. Commun. 2009, 37, 65-73. [CrossRef]

22. Gao, L.; Ma, W.; Chen, J.; Wang, K.; Li, J.; Wang, S.; Bekes, F.; Appels, R.; Yan, Y. Characterization and comparative analysis of wheat high molecular weight glutenin subunits by SDS-PAGE, RP-HPLC, HPCE, and MALDI-TOF-MS. J. Agric. Food Chem. 2010, 58, 2777-2786. [CrossRef]

23. Yan, X.; Liu, W.; Yu, Z.; Han, C.; Zeller, F.J.; Hsam, S.L.; Yan, Y. Rapid separation and identification of wheat HMW glutenin subunits by UPLC and comparative analysis with HPLC. Aust. J. Crop Sci. 2014, 8, 140-147.

24. Zhang, Q.; Dong, Y.; An, X.; Wang, A.; Zhang, Y.; Li, X.; Gao, L.; Xia, X.; He, Z.; Yan, Y. Characterization of HMW glutenin subunits in common wheat and related species by matrix-assisted laser desorption/ionization time-of-flight mass spectrometry (MALDI-TOF-MS). J. Cereal Sci. 2008, 47, 252-261. [CrossRef]

25. Jang, Y.-R.; Beom, H.-R.; Altenbach, S.B.; Lee, M.-K.; Lim, S.-H.; Lee, J.-Y. Improved method for reliable HMW-GS identification by RP-HPLC and SDS-PAGE in common wheat cultivars. Molecules 2017, 22, 1055. [CrossRef] [PubMed]

26. Jang, Y.-R.; Kim, S.; Sim, J.-R.; Lee, S.-B.; Lim, S.-H.; Kang, C.-S.; Choi, C.; Goo, T.-W.; Lee, J.-Y. High-throughput analysis of high-molecular weight glutenin subunits in 665 wheat genotypes using an optimized MALDI-TOF-MS method. 3 Biotech 2021, 11, 1-8. [CrossRef] [PubMed]

27. Chandra, D.; Timmick, S.; Goodwine, C.; Vecchiarello, N.; Shastry, D.G.; Mullerpatan, A.; Trasatti, J.P.; Cramer, S.; Karande, P. Design of peptide ligands for affinity purification of human growth hormone. J. Chem. Technol. Biotechnol. 2019, 94, $2345-2354$. [CrossRef]

28. Outlaw, V.K.; Kreitler, D.F.; Stelitano, D.; Porotto, M.; Moscona, A.; Gellman, S.H. Effects of Single $\alpha$-to- $\beta$ Residue Replacements on Recognition of an Extended Segment in a Viral Fusion Protein. ACS Infect. Dis. 2020, 6, 2017-2022. [CrossRef]

29. Perdomo-Abúndez, F.C.; Vallejo-Castillo, L.; Vázquez-Leyva, S.; López-Morales, C.A.; Velasco-Velázquez, M.; Pavón, L.; PérezTapia, S.M.; Medina-Rivero, E. Development and validation of a mass spectrometric method to determine the identity of rituximab based on its microheterogeneity profile. J. Chromatogr. B 2020, 1139, 121885. [CrossRef]

30. Timmick, S.M.; Vecchiarello, N.; Goodwine, C.; Crowell, L.E.; Love, K.R.; Love, J.C.; Cramer, S.M. An impurity characterization based approach for the rapid development of integrated downstream purification processes. Biotechnol. Bioeng. 2018, 115, 2048-2060. [CrossRef]

31. Zhang, B.; Jeong, J.; Burgess, B.; Jazayri, M.; Tang, Y.; Zhang, Y.T. Development of a rapid RP-UHPLC-MS method for analysis of modifications in therapeutic monoclonal antibodies. J. Chromatogr. B 2016, 1032, 172-181. [CrossRef]

32. Liu, L.; Ikeda, T.M.; Branlard, G.; Pena, R.J.; Rogers, W.F.; Lerner, S.E.; Kolman, M.A.; Xia, X.; Wang, L.; Ma, W. Comparison of low molecular weight glutenin subunits identified by SDS-PAGE, 2-DE, MALDI-TOF-MS and PCR in common wheat. BMC Plant Biol 2010, 10, 124-148. [CrossRef] [PubMed]

33. Dupont, F.; Chan, R.; Lopez, R. Molar fractions of high-molecular-weight glutenin subunits are stable when wheat is grown under various mineral nutrition and temperature regimens. J. Cereal Sci. 2007, 45, 134-139. [CrossRef]

34. Naeem, H.A.; Sapirstein, H.D. Ultra-fast separation of wheat glutenin subunits by reversed-phase HPLC using a superficially porous silica-based column. J. Cereal Sci. 2007, 46, 157-168. [CrossRef]

35. Kazman, M.; Lein, V. Cytological and SDS-PAGE characterization of 1994-95-grown European wheat cultivars. Ann. Wheat Newslett. 1996, 42, 86-92.

36. Branlard, G.; Dardevet, M.; Amiour, N.; Igrejas, G. Allelic diversity of HMW and LMW glutenin subunits and omega-gliadins in French bread wheat (Triticum aestivum L.). Genet. Resour. Crop Evol. 2003, 50, 669-679. [CrossRef]

37. Cho, S.-W.; Roy, S.K.; Chun, J.-B.; Cho, K.; Park, C.S. Overexpression of the Bx7 high molecular weight glutenin subunit on the Glu-B1 locus in a Korean wheat landrace. Plant Biotechnol. Rep. 2017, 11, 97-105. [CrossRef]

38. Lerner, S.; Ponzio, N.; Rogers, W. Relationship of Over-Expression of High Molecular Weight Glutenin Subunit Bx7 with Gluten Strength. In Proceedings of the 10th International Wheat Genetics Symposium, Paestum, Italy, 1-6 September 2003; pp. 1360-1362.

39. Zheng, W.; Peng, Y.; Ma, J.; Appels, R.; Sun, D.; Ma, W. High frequency of abnormal high molecular weight glutenin alleles in Chinese wheat landraces of the Yangtze-River region. J. Cereal Sci. 2011, 54, 401-408. [CrossRef]

40. Singh, N.; Shepherd, K.; Cornish, G. A Simplified SDS-PAGE Procedure for Separating. J. Cereal Sci. 1991, 14, 203-208. [CrossRef]

41. Melas, V.; Morel, M.-H.; Autran, J.-C.; Feillet, P. Simple and rapid method for purifying low molecular weight subunits of glutenin from wheat. Cereal Chem. 1994, 71, 234-237. 